Article

\title{
Family Support and Social Support Associated with National Essential Public Health Services Utilization among Older Migrants in China: A Gender Perspective
}

\author{
Wangnan Cao, Qingping Yun, Chun Chang and Ying Ji *(D) \\ Department of Social Medicine and Health Education, School of Public Health, Peking University, \\ Beijing 100191, China; wangnancao@bjmu.edu.cn (W.C.); 1711110152@bjmu.edu.cn (Q.Y.); \\ changchun@bjmu.edu.cn (C.C.) \\ * Correspondence: jiyingpku@163.com; Tel.: +86-10-82801743-803
}

\section{check for} updates

Citation: Cao, W.; Yun, Q.; Chang, C.; Ji, Y. Family Support and Social Support Associated with National Essential Public Health Services Utilization among Older Migrants in China: A Gender Perspective. Int. J. Environ. Res. Public Health 2022, 19, 1610. https://doi.org/10.3390/ ijerph19031610

Academic Editor: Paul B.

Tchounwou

Received: 30 November 2021

Accepted: 24 January 2022

Published: 30 January 2022

Publisher's Note: MDPI stays neutral with regard to jurisdictional claims in published maps and institutional affiliations.

Copyright: (C) 2022 by the authors. Licensee MDPI, Basel, Switzerland. This article is an open access article distributed under the terms and conditions of the Creative Commons Attribution (CC BY) license (https:// creativecommons.org/licenses/by/ $4.0 /)$.

\begin{abstract}
China provides National Essential Public Health Services (NEPHS) free of charge to all citizens to ensure access to essential health services. The present study aimed to explore the associations between different sources of support and NEPHS service utilization among older migrants in China with a gender perspective. We used a national cross-sectional dataset derived from the 2015 China Migrants Dynamic Survey. Participants were included if they were aged $\geq 60$ years and without household registration at the residence. Among 1989 participants, 35.2\% enrolled in a free physical examination in the past year: $34.6 \%$ for males and $35.9 \%$ for females. Among male participants, having more local friends ( $\mathrm{OR}=1.47,95 \% \mathrm{CI}: 1.09,1.99)$ and having insurance at the residence $(\mathrm{OR}=1.75,95 \% \mathrm{CI}: 1.03,2.96)$ were associated with enrolment in a free physical examination after controlling for age, education, and self-reported health status. Two additional factors, marital status and family structure, were found for female participants to be associated with enrolment in a free physical examination. NEPHS service utilization was far from satisfactory among older migrants in China, and both family support and social support played a role in it. There are common and unique factors associated with NEPHS service utilization in terms of gender.
\end{abstract}

Keywords: older migrants; National Essential Public Health Service; China; social support; family support; service utilization

\section{Introduction}

Health for all has become one of the critical efforts to achieve sustainable development goals (SDGs) worldwide and in China [1]. China provides National Essential Public Health Services (NEPHS) free of charge since 2009 to all citizens to ensure access to essential services (e.g., medical check-ups and chronic disease follow-up), regardless of gender, age, income, and place of residence. Compared to the general local population, older migrants are a vulnerable subpopulation reported with poor NEPHS utilization in the existing literature [2].

China has a large and increasing number of older migrants given population aging and rapid economic and social development. The number of older migrants aged over 60 reached 9.34 million, accounting for $7.2 \%$ of the total migrants [2]. Poor social interaction is commonly observed among older migrants [3,4], probably due to limited accessibility to local resources, difficulties in adapting to the local cultures, and limited capabilities to sustain the original network or develop new support networks [5,6]. To address these needs of migrants, China launched Essential Public Service Equalization for Migrants in 2013. Understanding the determinants of service utilization among older migrants becomes pressing in order to guide resource allocation, program design, and implementation.

We identified five publications in the existing literature that explored the prevalence and potential factors associated with NEPHS utilization among older migrants in 
China [7-11]. In general, these studies found that NEPHS utilization was unsatisfactory, e.g., 58\% not establishing a health record, $64 \%$ not enrolling in a yearly medical check-up, and $46 \%$ not seeking medical service when needed. Identified barriers to NEPHS utilization included limited-service accessibility [12], poor health status, a limited number of local friends, and lacking health insurance [7-11]. Some of these identified barriers fell into the domain of support, which is an enabling factor of service utilization $[13,14]$. However, these studies did not differentiate different sources of support, e.g., family support and broader social support. Another limitation in the existing literature is lacking a particular gender perspective. We believe that gender difference should be prominent in terms of service utilization among older migrants, given the gender role differences in the family and different gender expectations in Chinese society.

The present study aimed to explore the associations between different sources of support and NEPHS utilization among older migrants in China from a gender perspective. Support was categorized into family support and social support in the present study, and we separated analyses for male and female migrants.

\section{Materials and Methods}

\subsection{Data Sources}

The data used in the present study were from a national cross-sectional dataset derived from the 2015 China Migrants Dynamic Survey (CMDS). CMDS is the largest survey in China among migrants, and the surveyed sample is highly representative due to its rigorous sampling strategy (a stratified, multi-stage, scale-oriented probability proportionate to the size method) and validated data collection process. More details can be found in the handbook [15], and its methods have been validated and reported in several previous studies [16-19]. Consistent with the NEPHS guideline, older migrants in the present study are defined as older people aged 60 years or older whose household registration is not in the local area but who have been living in the local area longer than a month. Two key NEPHS utilization indicators were used, including enrolment in a free physical examination for all migrants and enrolment in a chronic disease follow-up for migrants who have physician-diagnosed chronic diseases. Chronic diseases here are limited to hypertension and diabetes, per NEPHS guidelines.

\subsection{Extraction of the Study Population}

We extracted households with older adults aged 60 years or older from the 206,000 households in the 2015 CMDS data. If two older people were registered in the same household, random numbers were used to select one for inclusion in the study. In total, 9242 samples were obtained. Given the population risk profile and available resources, different age cut-offs (65 years cut-off to enroll in a free physical examination while 60 years cut-off to enroll in a chronic disease follow-up) were used per NEPHS service guideline. To analyze the enrolment in free physical examinations, we included 1989 individuals aged 65 years or older who had lived locally for more than six months. To analyze the enrolment in the chronic disease follow-up, we included 899 individuals aged 60 years or older who had lived locally for more than six months and had physician-diagnosed hypertension and/or diabetes mellitus.

\subsection{Measurement of Variables}

Demographics and health status: Gender, age, highest education obtained, and location of residence (Eastern, Central, Western, and Northeast per Administrative Divisions of the People's Republic of China). The respondents were asked to self-rate their health status (healthy, unhealthy but able to take care of oneself, and unhealthy and unable to take care of oneself) and reported if they had a confirmed diagnosis for hypertension and/or diabetes by a physician.

NEPHS utilization: Two questions were asked: "Have you enrolled in a free physical examination provided by a community health center in the past year?" and "Have you 
enrolled in any follow-up services due to your hypertension or diabetes status in the past year?" Follow-up services included outpatient clinic visits, telephone follow-ups, or home visits. Responses included yes or no.

Family and social support: Two sources of support were asked, including family support and social support [20,21]. Information on family support included average monthly household income (obtained by dividing the total average monthly household income by the number of household members: CNY <1000, 1000-2000, >2000), marital status (widowed/single, married), and family structure (live alone, live with a spouse, live with children or grandchildren, and live with children and grandchildren). Information on social support included the number of local friends $((\geq 4$ vs. $<4)$ and health insurance status (no insurance, insurance at residence, and insurance in their hometown).

\subsection{Statistical Analysis}

Percentages were used to describe the basic information, and chi-square tests were performed for the one-way analysis. Logistic regression was conducted to explore the relationship between each support variable and NEPHS utilization. The odds ratio (OR) and $95 \%$ confidence intervals (CI) were used to describe the relationship between variables after controlling for background variables including age, education, health status, and location of residence. We did separate analyses for male and female participants. A twosided test was performed set at $\alpha=0.05$. The study used SPSS 22.0 Windows (SPSS, Inc., Chicago, IL, USA) to analyze the data.

\section{Results}

3.1. Characteristics of Participants Eligible for Free Enrolment in a Free Physical Examination (Aged 65 Years and Older)

Among a total of 1989 participants who were eligible for enrolment in a free physical examination, half $(51.9 \%)$ were males $(N=1032)$ and half $(48.1 \%)$ were females $(N=957)$. Approximately half were aged between 65 and 70 years old, and the other half were older than 70 years. More than half had an education level below the primary school. Relatively more older people moved to the West $(46.2 \%)$ and East $(30.9 \%)$, and less to the Northeast $(14.6 \%)$ and Central $(8.4 \%)$. The majority $(83.4 \%)$ of the participants rated themselves as healthy and $28.6 \%$ of the older migrants reported that they had hypertension and/or diabetes diagnosed by a physician. There was no gender difference in terms of these background characteristics. Of the 1989 survey respondents, $35.2 \%$ enrolled in a free physical examination in the past year, $34.6 \%$ for males and $35.9 \%$ for females $(p>0.05$ between males and females) (Table 1$)$.

The majority $(70.0 \%)$ of the participants had health insurance in their hometown, $13.6 \%$ had health insurance at their residence, and $16.3 \%$ have neither. Two-thirds of the participants were married, 55.3\% had less than three family members living together, and the average monthly household income was evenly distributed (CNY 35.3\% < 1000, $34.5 \%$ 1000-2000, 30.1\% $\geq 2000$ ). Two-thirds of the participants had more than 4 local friends, $23.8 \%$ had $1-3$ friends, and $9.1 \%$ had no local friends.

Among male participants, the number of local friends and health insurance status were associated with the enrolment in a free physical examination in the past year after controlling for age, education, and self-reported health status. Specifically, compared to participants with 0-3 local friends, participants with four or more local friends were more likely to be enrolled in a free physical examination in the past year $(\mathrm{OR}=1.47$, $95 \%$ CI: $1.09,1.99)$. Compared to participants with no insurance, participants with health insurance at their residence were more likely to be enrolled in a free physical examination (OR $=1.75,95 \%$ CI: 1.03, 2.96), and participants with health insurance in their hometown were also more likely to be enrolled in a free physical examination $(\mathrm{OR}=1.83$, $95 \%$ CI: 1.21, 2.77). Household income, marital status, and family structure were not associated with enrolment in a free physical examination (Table 2). 
Table 1. Participants' characteristics in terms of enrolment in the free physical examinations among older migrants $(N=1989)$.

\begin{tabular}{|c|c|c|c|c|c|c|c|c|c|}
\hline \multirow[b]{2}{*}{$\begin{array}{l}\text { Variable } \\
\text { Name }\end{array}$} & \multirow[b]{2}{*}{ Category } & \multicolumn{4}{|c|}{ Male } & \multicolumn{4}{|c|}{ Female } \\
\hline & & $\begin{array}{l}\text { Total Par- } \\
\text { ticipants } \\
N(\%)\end{array}$ & $\begin{array}{c}\text { Participation } \\
\text { Enrolled in } \\
\text { Free Physical } \\
\text { Examination } \\
n(\%)\end{array}$ & $x^{2}$ & $p$ & $\begin{array}{c}\text { Total } \\
\text { Participants } \\
N(\%)\end{array}$ & $\begin{array}{l}\text { Participation } \\
\text { Enrolled in } \\
\text { Free Physical } \\
\text { Examination } \\
n(\%)\end{array}$ & $x^{2}$ & $p$ \\
\hline $\begin{array}{c}\text { Total } \\
\text { sample }\end{array}$ & - & $1032(100.0)$ & $357(34.6)$ & & & $957(100.0)$ & 344 (35.9) & & \\
\hline Age (years) & $\begin{array}{c}65-70 \\
70+\end{array}$ & $\begin{array}{l}563(54.6) \\
469(45.4)\end{array}$ & $\begin{array}{l}193(34.3) \\
164(35.0)\end{array}$ & 0.05 & 0.82 & $\begin{array}{l}484(50.6) \\
473(49.4)\end{array}$ & $\begin{array}{l}191(39.5) \\
153(32.3)\end{array}$ & 5.26 & $0.02 *$ \\
\hline $\begin{array}{l}\text { Education } \\
\text { level }\end{array}$ & $\begin{array}{c}\text { Elementary school } \\
\text { or below } \\
\text { Junior school } \\
\text { or above }\end{array}$ & 437 (49.4) & $164(37.5)$ & 2.89 & 0.09 & $257(26.9)$ & $\begin{array}{l}234(33.4) \\
110(42.8)\end{array}$ & 7.17 & $0.007 * *$ \\
\hline \multirow[t]{3}{*}{$\begin{array}{l}\text { Health self- } \\
\text { assessment }\end{array}$} & Healthy & $879(85.2)$ & 313 (35.6) & 3.09 & 0.21 & 779 (81.4) & $282(36.2)$ & 8.37 & $0.04 *$ \\
\hline & $\begin{array}{c}\text { Unhealthy but able } \\
\text { to take care } \\
\text { of oneself }\end{array}$ & $135(13.1)$ & $40(29.6)$ & & & $146(15.3)$ & $57(39.0)$ & & \\
\hline & $\begin{array}{c}\text { Unable to take care } \\
\text { of oneself }\end{array}$ & $18(1.7)$ & $4(22.2)$ & & & $32(3.3)$ & $5(15.6)$ & & \\
\hline $\begin{array}{l}\text { Monthly } \\
\text { personal } \\
\text { income per }\end{array}$ & $<1000$ & $353(34.2)$ & $114(32.3)$ & 1.52 & 0.47 & $350(36.6)$ & $128(36.6)$ & 0.92 & 0.63 \\
\hline $\begin{array}{l}\text { income per } \\
\text { household } \\
(\mathrm{CNY})\end{array}$ & $\begin{array}{l}1000-2000 \\
>2000\end{array}$ & $\begin{array}{l}346(33.5) \\
333(32.3)\end{array}$ & $\begin{array}{l}127(36.7) \\
116(34.8)\end{array}$ & & & $\begin{array}{l}341(35.6) \\
266(27.8)\end{array}$ & $\begin{array}{l}116(34.0) \\
100(37.6)\end{array}$ & & \\
\hline \multirow{2}{*}{$\begin{array}{l}\text { Marital } \\
\text { status }\end{array}$} & Widowed/single & $225(21.8)$ & $66(29.3)$ & 3.52 & 0.06 & $435(45.5)$ & $134(30.8)$ & 9.16 & $0.02 *$ \\
\hline & Married & 807 (78.2) & $291(36.1)$ & & & $522(54.5)$ & $210(40.2)$ & & \\
\hline \multirow[t]{4}{*}{$\begin{array}{l}\text { Family } \\
\text { structure }\end{array}$} & Live alone & $64(6.2)$ & $18(28.1)$ & 6.68 & 0.08 & $62(6.5)$ & $29(46.8)$ & 1.98 & $0.007^{* *}$ \\
\hline & Live with spouse & 409 (39.6) & $160(39.1)$ & & & $275(28.7)$ & $116(42.2)$ & & \\
\hline & $\begin{array}{l}\text { Live with children } \\
\text { or grandchildren }\end{array}$ & $184(17.8)$ & $61(33.2)$ & & & $158(16.5)$ & $53(33.5)$ & & \\
\hline & $\begin{array}{l}\text { Live with children } \\
\text { and grandchildren }\end{array}$ & $375(36.3)$ & $118(31.5)$ & & & $462(48.3)$ & $146(31.6)$ & & \\
\hline $\begin{array}{l}\text { Number of } \\
\text { local } \\
\text { friends }\end{array}$ & $<4$ & $303(29.4)$ & $84(27.7)$ & 8.95 & $0.003^{* *}$ & $362(37.8)$ & $100(27.6)$ & 17.51 & $<0.001^{* * *}$ \\
\hline \multirow{4}{*}{$\begin{array}{l}\text { Health } \\
\text { insurance }\end{array}$} & $\geq 4$ & $729(70.6)$ & $273(37.4)$ & & & $595(62.2)$ & $244(41.0)$ & & \\
\hline & $\begin{array}{l}\text { No health } \\
\text { insurance }\end{array}$ & $153(14.8)$ & $35(22.9)$ & 10.90 & $0.004 * *$ & $172(18.0)$ & $60(34.9)$ & 16.31 & $<0.001^{* * *}$ \\
\hline & $\begin{array}{l}\text { Health insurance } \\
\text { at residence }\end{array}$ & 139 (13.5) & $51(36.7)$ & & & $132(13.8)$ & $68(51.5)$ & & \\
\hline & $\begin{array}{l}\text { Health insurance } \\
\text { at hometown }\end{array}$ & 740 (71.7) & $271(36.6)$ & & & $653(68.2)$ & $216(33.1)$ & & \\
\hline \multirow[t]{4}{*}{$\begin{array}{l}\text { Residence } \\
\text { location }\end{array}$} & Eastern & 319 (30.9) & $93(29.2)$ & 14.60 & $0.002 * *$ & $292(30.5)$ & $74(25.3)$ & 21.66 & $<0.001^{* * *}$ \\
\hline & Central & $89(8.6)$ & $21(23.6)$ & & & $77(8.0)$ & $35(45.5)$ & & \\
\hline & Western & $468(45.4)$ & 185 (39.5) & & & $446(46.6)$ & $181(40.6)$ & & \\
\hline & Northeast & 154 (14.9) & $58(37.7)$ & & & $135(14.1)$ & $51(37.8)$ & & \\
\hline \multirow{2}{*}{$\begin{array}{l}\text { Diagnosed } \\
\text { hyperten- } \\
\text { sion or } \\
\text { diabetes }\end{array}$} & Yes & $269(26.1)$ & $106(39.4)$ & 3.72 & 0.05 & $299(31.2)$ & $114(38.1)$ & 0.90 & 0.34 \\
\hline & No & 763 (73.9) & 251 (32.9) & & & $658(68.8)$ & $230(35.0)$ & & \\
\hline
\end{tabular}


Table 2. Multivariate logistic regression on factors associated with enrolment in free physical examination.

\begin{tabular}{|c|c|c|c|c|c|}
\hline \multirow{2}{*}{ Variable Name } & \multirow{2}{*}{ Category } & \multicolumn{2}{|c|}{ Male } & \multicolumn{2}{|c|}{ Female } \\
\hline & & OR & $95 \%$ CI & OR & $95 \%$ CI \\
\hline \multirow[t]{3}{*}{$\begin{array}{l}\text { Monthly personal income } \\
\text { per household (CNY) }\end{array}$} & $\leq 1000$ & 1.00 & & 1.00 & \\
\hline & 1000-2000 & 1.31 & $0.95,1.81$ & 0.96 & $0.69,1.34$ \\
\hline & $>2000$ & 1.19 & $0.83,1.70$ & 1.15 & $0.78,1.70$ \\
\hline \multirow[t]{2}{*}{ Marital status } & Widowed/single & 1.00 & & & 1.00 \\
\hline & Married & 1.21 & $0.83,1.75$ & 1.55 * & $1.10,2.20$ \\
\hline \multirow[t]{4}{*}{ Family structure } & Live alone & 1.00 & & 1.00 & \\
\hline & Live with spouse & 1.37 & $0.72,2.60$ & 0.64 & $0.33,1.25$ \\
\hline & Live with children or grandchildren & 1.05 & $0.54,2.04$ & 0.53 & $0.28,1.01$ \\
\hline & Live with children and grandchildren & 1.08 & $0.58,2.01$ & $0.50 *$ & $0.28,0.90$ \\
\hline \multirow[t]{2}{*}{ Number of local friends } & $<4$ & 1.00 & & 1.00 & \\
\hline & $\geq 4$ & $1.47 *$ & $1.09,1.99$ & $1.63^{* *}$ & $1.21,2.20$ \\
\hline \multirow[t]{3}{*}{ Health insurance } & No health insurance & 1.00 & & & 1.00 \\
\hline & Health insurance at residence & $1.75 *$ & $1.03,2.96$ & $1.71 *$ & $1.05,2.79$ \\
\hline & Health insurance at hometown & $1.83^{* *}$ & $1.21,2.77$ & 0.83 & $0.57,1.21$ \\
\hline \multirow[t]{4}{*}{ Residence location } & Eastern & 1.00 & & 1.00 & \\
\hline & Central & 0.72 & $0.41,1.27$ & $2.43^{* *}$ & $1.38,4.25$ \\
\hline & Western & $1.68 * *$ & $1.20,2.34$ & $2.10^{* *}$ & $1.46,3.01$ \\
\hline & Northeast & 1.53 & $0.98,2.39$ & 1.52 & $0.94,2.45$ \\
\hline
\end{tabular}

The models were controlled for age, education, and health self-assessment. ${ }^{*} p<0.05,{ }^{* *} p<0.01$.

Among female participants, marital status, family structure, number of local friends, and health insurance status were associated with the enrolment in a free physical examination in the past year after controlling for age, education, and self-reported health status. Specifically, compared to widowed/single participants, married participants were more likely to be enrolled in a free physical examination in the past year $(\mathrm{OR}=1.55$, $95 \%$ CI: 1.10, 2.20). Compared to participants living alone, participants living with children and grandchildren were less likely to be enrolled in a free physical examination in the past year $(\mathrm{OR}=0.50,95 \% \mathrm{CI}$ : $0.28,0.90)$; no difference was found between participants living with a spouse. Compared to participants with 0-3 local friends, participants with four or more local friends were more likely to be enrolled in a free physical examination in the past year ( $\mathrm{OR}=1.63,95 \% \mathrm{CI}: 1.21,2.20)$. Compared to participants with no insurance, participants with health insurance at their residence were more likely to be enrolled in a free physical examination ( $\mathrm{OR}=1.71,95 \% \mathrm{CI}$ : 1.05, 2.79); no difference was found for participants with health insurance at their hometown. Household income was not associated with enrolment in a free physical examination (Table 2).

\subsection{Characteristics of Participants with Chronic Disease Eligible for Free Enrolment in a Follow-Up Service (Aged 60 Years and Older)}

Among a total of 899 older migrant participants with chronic disease eligible for free enrolment in a follow-up service, around half $(48.8 \%)$ of the older migrant population were males $(N=439)$ and half $(51.2 \%)$ were females $(N=460)$. Two-thirds $(65.9 \%)$ were aged less than 70 years. The majority of the participants had an education level below primary school. More participants live in the Western (44.5\%) and Eastern regions $(34.9 \%)$, and fewer in the Northeast $(13.9 \%)$ and Central $(6.7 \%)$. The majority $(74.1 \%)$ of survey respondents rated themselves as healthy. Among the 899 survey respondents with a chronic disease, $34.3 \%$ enrolled in a follow-up service in the past year, $34.6 \%$ for males and $33.9 \%$ for females ( $p>0.05$ between males and females) (Table 3 ). 
Table 3. Participants' characteristics in terms of enrolment in the chronic disease follow-up among older migrants $(N=899)$.

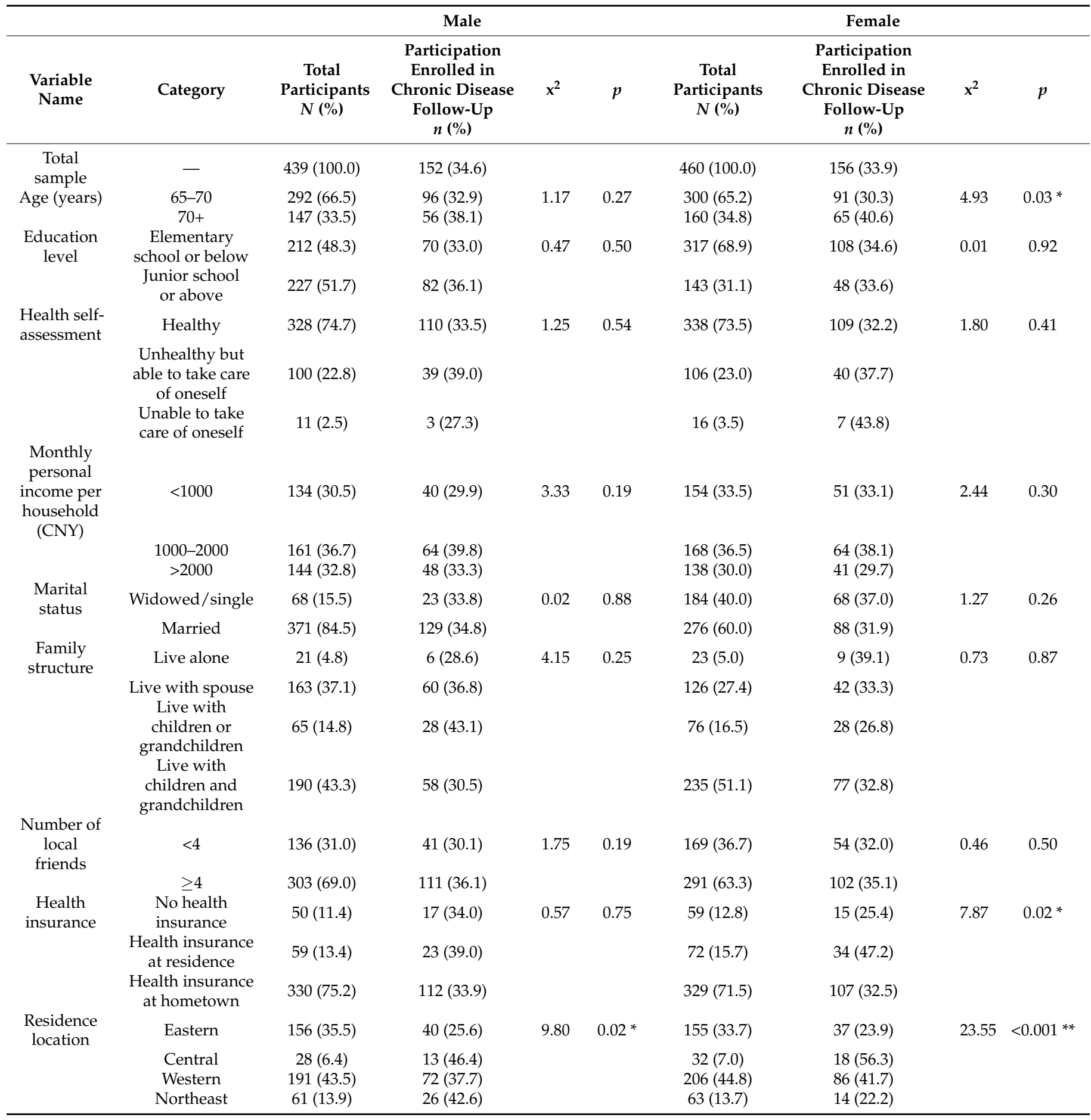

* $p<0.05,{ }^{* *} p<0.01$.

The majority (73.3\%) of the participants had health insurance in their hometown, $14.6 \%$ had health insurance at their residence, and $12.1 \%$ had neither. More than twothirds $(72.0 \%)$ of the participants were married, $50.9 \%$ had less than three family members living together, and the per capita monthly household income was evenly distributed (CNY 32.0\% < 1000, 36.6\% 1000-2000, 31.4\% $\geq 2000$ ). Of the survey respondents, $66.1 \%$ had four and more local friends, $24.7 \%$ had $1-3$ friends, and $9.2 \%$ had no local friends. The median number of local friends was 5 . 
Among male participants, we did not find any support-related variables associated with the enrolment in a follow-up service for chronic disease in the past year after controlling for age, education, and self-reported health status (Table 4).

Table 4. Multivariate logistic regression on factors associated with enrolment in chronic disease follow-up.

\begin{tabular}{|c|c|c|c|c|c|}
\hline \multirow{2}{*}{ Variable Name } & \multirow{2}{*}{ Category } & \multicolumn{2}{|c|}{ Male } & \multicolumn{2}{|c|}{ Female } \\
\hline & & OR & $95 \%$ CI & OR & $95 \%$ CI \\
\hline \multirow[t]{3}{*}{$\begin{array}{l}\text { Monthly personal income } \\
\text { per household (CNY) }\end{array}$} & $\leq 1000$ & 1.00 & & 1.00 & \\
\hline & $1000-2000$ & 1.60 & $0.96,2.67$ & 1.35 & $0.83,2.19$ \\
\hline & $>2000$ & 1.63 & $0.90,2.93$ & 1.10 & $0.62,1.95$ \\
\hline \multirow[t]{2}{*}{ Marital status } & Widowed/single & & & & \\
\hline & Married & 1.05 & $0.56,1.97$ & 0.83 & $0.51,1.36$ \\
\hline \multirow[t]{4}{*}{ Family structure } & Live alone & 1.00 & & 1.00 & \\
\hline & Live with spouse & 1.53 & $0.49,4.75$ & 0.78 & $0.27,2.25$ \\
\hline & Live with children or grandchildren & 2.10 & $0.65,6.78$ & 0.75 & $0.26,2.15$ \\
\hline & Live with children and grandchildren & 1.35 & $0.45,4.05$ & 0.63 & $0.24,1.65$ \\
\hline \multirow[t]{2}{*}{ Number of local friends } & $<4$ & & & & \\
\hline & $\geq 4$ & 1.29 & $0.82,2.03$ & 1.17 & $0.76,1.79$ \\
\hline \multirow[t]{3}{*}{ Health insurance } & No health insurance & 1.00 & & 1.00 & \\
\hline & Health insurance at residence & 0.99 & $0.43,2.28$ & $2.47 *$ & $1.07,5.69$ \\
\hline & Health insurance at hometown & 0.85 & $0.44,1.66$ & 1.25 & $0.63,2.46$ \\
\hline \multirow[t]{4}{*}{ Residence location } & Eastern & 1.00 & & 1.00 & \\
\hline & Central & $2.91 *$ & $1.23,6.87$ & $3.33^{* *}$ & $1.44,7.70$ \\
\hline & Western & $2.05^{* *}$ & $1.22,3.45$ & $2.13^{* *}$ & $1.29,3.52$ \\
\hline & Northeast & $2.59 * *$ & $1.29,5.21$ & 0.72 & $0.33,1.56$ \\
\hline
\end{tabular}

The models were controlled for age, education, and health self-assessment. ${ }^{*} p<0.05,{ }^{* *} p<0.01$.

Among female participants, after controlling for age, education, and self-reported health status, participants with health insurance at their residence were more likely than those with no insurance to be enrolled in a follow-up service for chronic disease $(\mathrm{OR}=2.47$, 95\% CI: 1.07, 5.69); no difference was found for participants with health insurance in their hometown. Other social-related variables were not associated with enrolment in a follow-up service for chronic disease (Table 4).

\section{Discussion}

The present study aimed to explore the associations between different sources of support and NEPHS utilization among older migrants in China from a gender perspective. We found a low NEPHS utilization among older migrants in China, and both family support and social support played a role in it. There are common (e.g., more local friends) and unique (e.g., family structure) support-related factors associated with NEPHS utilization in terms of gender. For example, having more local friends and having health insurance at the location of residence were associated with more NEPHS utilization for both genders. Married participants reported more NEPHS utilization than non-married participants, but this finding applied to females only.

We found low NEPHS utilization among older migrants in China, which was around half of the rates compared to the utilization among the local older population. The Fifth Health Services Survey in China in 2013 showed that $59.6 \%$ of the population aged 65 years or older had physical examinations in the past one year, while $71.3 \%$ of hypertensive patients aged 35 years or older had received follow-ups in the past three months [22]. This low utilization rate might be explained by imbalanced resources allocation across the country and limited service provisions at local facilities. We found that older migrants living in the Eastern region utilized NEPHS less than those living in other regions (27\% vs. 39\% for medical check-ups; $25 \%$ vs. 39\% for disease follow-up). The Eastern region receives the most health resources and NEPHS funding across all regions, but it attracts a large number 
of migrants, particularly a young working-age migrant population, which might place high pressure on the NEPHS service provisions. As a result, there might be limited workforce or resources allocated to the older population. Therefore, older migrants were a particularly disadvantaged subpopulation in enrolling in NEPHS service utilization, which places them at a higher risk of late disease diagnosis, poor health status, and high disease burden.

In terms of gender, two common factors associated with NEPHS utilization were health insurance status and the number of local friends. Having health insurance at their residence allows them to access information easier and functions as a sign of good social integration and connectiveness to the local community [23]. Similarly, a large number of local friends also implies a high level of social integration and social support [24,25], and also good accessibility to local resources [26].

Low social support was found among this older migrant population due to low coverage of health insurance at their residence and a low number of local friends. The health insurance coverage rate $(84 \%)$ was far below the rate among the counterpart local population, with a national average of $98.4 \%$ for local people aged 60 years and older [22]. One possible reason is the requirement of the health insurance enrollment fee (CNY 250-320 per year depending on the location), which migrants may have to pay both in their hometown (even if they do not live there) and their residence location in order to have comprehensive medical coverage. We also found that $10 \%$ of the older migrants had no local friends, with a median number of friends of five. This was far lower than the number (5-30) of friends reported by local older people, although the number was sometimes not directly comparable due to various samples of participants and different measurements on friends (e.g., closeness level) [27-29].

Two family support-related variables, marital status and family structure, were associated with NEPHS utilization, but only among female migrants. We found that married participants were more likely to be enrolled in a physical examination, which might be explained by the fact that older migrants were more dependent on family resources to utilize health care services [30-32] and combined resources from the couples. Unexpectedly, we found that an increased family size (living with children and grandchildren) was a barrier in NEPHS service utilization among female migrants. A possible reason could be that an increased family size means an increase in household activities such as home care particularly for female household heads and therefore limited time to utilize care. Few studies have investigated this family structure issue associated with service utilization, and further exploration is suggested $[33,34]$.

We found household income was not associated with enrolment in a physical examination and chronic disease follow-up service, which was different from previous studies focusing on treatment-related service unitization [4]. Since NEPHS services were all free of charge, income should not be a barrier in accessing these services. However, there are other costs associated with service unitization, such as transportation costs to the local facility and time costs needed to spend on the service.

This study is subjected to some limitations. First, this was a cross-sectional study, and no causal inferences can be made based on these data. In the present study, we used association (rather than casual) terms to interpret our findings. Second, our measurements of family support and social support were self-constructed based on existing variable information and might not be comprehensive. To minimize potential bias, we took only objective measures related to support in the database and performed quality checks on the measures we included. Other key variables that reflected these supports (e.g., emotional support) might not have been captured in the survey. Third, we used self-reported data, and there might be recall bias given that the participants were older. However, the questionnaire was validated particularly among this population, and all interviewers were well-trained and experienced in collecting these data.

Despite these limitations, the present study explored the relationships between two sources of support (family support and social support) and NEPHS service utilization among the older migrant population. Both common and unique factors in terms of gender 
were explored to better aid resources allocation and programs design. CMDS is the largest and most representative survey targeted at old migrants, which makes the findings solid and valuable for policymaking.

\section{Conclusions}

Despite the fact that NEPHS services in China are free of charge to anyone, the NEPHS service utilization was far from satisfactory among older migrants-a highly vulnerable subpopulation needing support. For both genders, we found two social support indicators associated with NEPHS service utilization, including a large number of local friends and health insurance at the location of residence. We also found that married participants and participants living in a small household were more likely to use NEPHS services, but this finding applied to female migrants only. We conclude that a supportive community with easy access to health insurance and opportunities to know peers and build relationships is desirable for older migrants in China. Unmarried older migrants and migrants living in large households with children and grandchildren are particularly vulnerable and should be given extra attention. NEPHS is essential in ensuring health equity and achieving universal health coverage in China, but we acknowledge that sufficient NEPHS services' utilization requires active participation by the individual (the user side) and also strong promotion from the government (the supply side).

Author Contributions: W.C. and Y.J. designed the study and analyzed the data; W.C. and Q.Y. drafted the manuscript; C.C. substantially revised the manuscript. All authors revised the manuscript and approved the final draft. All authors have read and agreed to the published version of the manuscript.

Funding: This research received no external funding.

Institutional Review Board Statement: Not applicable.

Informed Consent Statement: Not applicable.

Data Availability Statement: Restrictions apply to the availability of these data. Data were obtained from the Migrants Population Service Center, National Health Commission P.R. China and are available from the authors with the permission of the National Health Commission P.R. China.

Acknowledgments: We thank the Migrant Population Service Center, National Health Commission P.R. China for the support in providing the database (2015 Migrant Dynamics Monitoring Survey in China) for the study.

Conflicts of Interest: The authors declare no conflict of interest.

\section{References}

1. Global Conference on Primary Health Care. Available online: https://www.who.int/teams/primary-health-care/conference (accessed on 8 October 2021).

2. Department of Family Planning Services and Management in Migrant Population NHaFPC. Report on China Migrant Population Development 2017; China Population Publishing House: Beijing, China, 2017.

3. Kim, B.J.; Sangalang, C.C.; Kihl, T. Effects of acculturation and social network support on depression among elderly Korean immigrants. Aging Ment. Health 2012, 16, 787-794. [CrossRef] [PubMed]

4. Zhang, X.; Yu, B.; He, T.; Wang, P. Status and determinants of health services utilization among elderly migrants in China. Glob. Health Res. Policy 2018, 3, 1-10. [CrossRef] [PubMed]

5. Hong, H.; Shuo, W. Social Support and Life Satisfaction of Young Migrants. Popul. Res. 2016, 40, 45-57. (In Chinese)

6. Liang, J.; Shi, Y.; Osman, M.; Shrestha, B.; Wang, P. The Association between Social Integration and Utilization of Essential Public Health Services among Internal Migrants in China: A Multilevel Logistic Analysis. Int. J. Environ. Res. Public Health 2020, 17, 6524. [CrossRef] [PubMed]

7. Jing, Z.; Wang, Y.; Ding, L.; Tang, X.; Feng, Y.; Zhou, C. Effect of social integration on the establishment of health records among elderly migrants in China: A nationwide cross-sectional study. BMJ Open 2019, 9, e034255. [CrossRef] [PubMed]

8. Long, C.; Tang, S.; Wang, R.; Ji, L.; Wang, Y.; Wu, T.; Li, Z.; Feng, Z. The migrating mediators and the interaction associated with the use of essential public health services: A cross-sectional study in Chinese older migrants. BMC Geriatr. 2020, 20, 475. [CrossRef] [PubMed]

9. $\quad$ Long, C.; Wang, R.; Feng, D.; Ji, L.; Feng, Z.; Tang, S. Social Support and Health Services Use in People Aged over 65 Years Migrating within China: A Cross-Sectional Study. Int. J. Environ. Res. Public Health 2020, 17, 4651. [CrossRef] 
10. Tang, D.; Wang, J. Basic Public Health Service Utilization by Internal Older Adult Migrants in China. Int. J. Environ. Res. Public Health 2021, 18, 270. [CrossRef]

11. Tang, S.; Long, C.; Wang, R.; Liu, Q.; Feng, D.; Feng, Z. Improving the utilization of essential public health services by Chinese elderly migrants: Strategies and policy implication. J. Glob. Health 2020, 10, 010807. [CrossRef]

12. Reed, C.; Rabito, F.A.; Werthmann, D.; Smith, S.; Carlson, J.C. Factors associated with using alternative sources of primary care: A cross-sectional study. BMC Health Serv. Res. 2019, 19, 1-9. [CrossRef]

13. Babitsch, B.; Gohl, D.; von Lengerke, T. Re-revisiting Andersen's Behavioral Model of Health Services Use: A systematic review of studies from 1998-2011. GMS Psycho Soc. Med. 2012, 9, 91-109.

14. Hone, T.; Rasella, D.; Barreto, M.L.; Majeed, A.; Millett, C. Association between expansion of primary healthcare and racial ine-qualities in mortality amenable to primary care in Brazil: A national longitudinal analysis. PLoS Med. 2017, 14, e1002306. [CrossRef] [PubMed]

15. National Health and Family Planning Commission of the People's Republic of China. Handbook of Dynamic Monitoring on Migrants in China; National Health and Family Planning Commission: Beijing, China, 2015.

16. Han, J.; Meng, Y. Institutional differences and geographical disparity: The impact of medical insurance on the equity of health services utilization by the floating elderly population-evidence from China. Int. J. Equity Health 2019, 18, 1-14. [CrossRef] [PubMed]

17. Chen, H.; Zhu, Z.; Chang, J.; Gao, Y. The effects of social integration and hometown identity on the life satisfaction of Chinese rural migrants: The mediating and moderating effects of a sense of belonging in the host city. Health Qual. Life Outcomes 2020, 18, 1-9. [CrossRef]

18. Xia, Y.; Ma, Z. Relative deprivation, social exclusion, and quality of life among Chinese internal migrants. Public Health 2020, 186, 129-136. [CrossRef]

19. Ji, Y.; Liu, S.; Zhao, X.; Jiang, Y.; Zeng, Q.; Chang, C. Smoking and its determinants in Chinese internal migrants: Nationally representative cross-sectional data analyses. Nicotine Tob. Res. 2016, 18, 1719-1726. [CrossRef]

20. Uchino, B.N.; Cacioppo, J.T.; Kiecolt-Glaser, J.K. The relationship between social support and physiological processes: A review with emphasis on underlying mechanisms and implications for health. Psychol. Bull. 1996, 119, 488-531. [CrossRef]

21. DiMatteo, M.R. Social support and patient adherence to medical treatment: A meta-analysis. Health Psychol. 2004, 23, 207-218. [CrossRef]

22. Statistical Information Center of National Health and Family Planning Commission. An Analysis Report of National Health Services Survey in China, 2013; National Health and Family Planning Commission: Beijing, China, 2015.

23. Song, X.; Zou, G.-Y.; Shi, J.-R.; Lin, Y.-W.; Ling, L. Health service utilization of internal migrants in Guangdong province: From the family migration perspective. Mod. Prev. Med. 2017, 44, 1454-1469. (In Chinese)

24. Chen, X.; Stanton, B.; Gong, J.; Fang, X.; Li, X. Personal Social Capital Scale: An instrument for health and behavioral research. Health Educ. Res. 2008, 24, 306-317. [CrossRef]

25. Wang, P.; Chen, X.; Gong, J.; Jacques-Tiura, A.J. Reliability and Validity of the Personal Social Capital Scale 16 and Personal Social Capital Scale 8: Two Short Instruments for Survey Studies. Soc. Indic. Res. 2014, 119, 1133-1148. [CrossRef]

26. Wang, J.; Wu, Y.; Zhou, B.; Zhang, S.; Zheng, W.; Chen, K. Factors associated with non-use of inpatient hospital care service by elderly people in China. Health Soc. Care Community 2009, 17, 476-484. [CrossRef] [PubMed]

27. Chen, H.; Zhu, Z.; Sun, D.; Wang, X. The physical and psychological health of migrants in Guangzhou, China: How does neighborhood matter? INQUIRY: J. Health Care Organ. Provis. Financ. 2016, 53, 0046958016668065. [CrossRef] [PubMed]

28. Liu, Q.; Pan, H. Investigation on Life Satisfaction of Rural-to-Urban Migrant Workers in China: A Moderated Mediation Model. Int. J. Environ. Res. Public Health 2020, 17, 2454. [CrossRef] [PubMed]

29. Li, C.-C.; Meng, X.-H.; Wang, J.-R.; Ma, H.-J.; Chen, C.; Liu, Y.-Q. Association between sociodemographic, psychosocial, lifestyle factors, and self-reported health among migrant laborers in China. J. Chin. Med. Assoc. 2017, 80, 204-211. [CrossRef] [PubMed]

30. Wang, Q. Health of the Elderly Migration Population in China: Benefit from Individual and Local Socioeconomic Status? Int. J. Environ. Res. Public Health 2017, 14, 370. [CrossRef] [PubMed]

31. Liu, S.; Hu, C.X.J.; Mak, S. Comparison of Health Status and Health Care Services Utilization between Migrants and Natives of the Same Ethnic Origin-The Case of Hong Kong. Int. J. Environ. Res. Public Health 2013, 10, 606-622. [CrossRef] [PubMed]

32. Joung, I.M.A.; van der Meer, J.B.W.; MacKenbach, J.P. Marital Status and Health Care Utilization. Int. J. Epidemiol. 1995, 24, 569-575. [CrossRef]

33. He, Y.; Shi, H.; He, N.; Li, X.; Ren, Z.; Fan, X.; Guo, X.; Cha, S.; Qiao, S.; Zhan, H.; et al. Health management service utilization and affecting factor among older immigrants in three northeast provinces. Chin. J. Gerontol. 2021, 3, 1330-1332. (In Chinese)

34. Du, B.; Cao, G.; Xu, F. Analysis on health status and medical service utilization among the migrant elderly in China. Chin. J. Health Policy 2018, 11, 10-16. (In Chinese) 